\title{
Microleakage of Composite Inlays Luted with Self-adhesive Cements
}

\author{
Lise DP*, Lopes GC, Maia HP and Baratieri LN \\ Department of Operative Dentistry, Federal University of Santa Catarina, Brazil
}

\begin{abstract}
Objective: To evaluate the microleakage of three self-adhesive cements and one etch \& rinse resin cement on dentin and enamel interfaces.

Methods: Forty-eight inlays preparations $(n=12)$ with enamel and dentin margins were performed on extracted teeth. After impressions, indirect composite inlays were manufactured and luted with self-adhesive resin cements (RelyX U100, Maxcem or SpeedCem) or an etch \& rinse resin cement (Nexus 3). Restored teeth were thermocycled and immersed in a silver nitrate solution. Specimens were cut through restorations, surfaces were photographed and microleakage was measured with aid of computer software (Image J). Statistical analysis was realized with KruskalWallis nonparametric test $(\mathrm{P}<0.05)$.
\end{abstract}

Results: Statistical analysis of enamel-cement interfaces showed that Nexus provided better marginal sealing than Speedcem $(p<0.05)$. Considering dentin-cement interface, RelyX U100 presented the smaller microleakage degree than Speedcem and Maxcem $(p<0.05)$.

Conclusions: Among self-adhesive resin cements, RelyX U100 showed better sealing ability of enamel and dentin margins and its performance was comparable to Nexus 3 .

Keywords: Self-adhesive cement; Microleakage; Luting

\section{Introduction}

Direct resin composite restorations are not indicated for large cavities in posterior teeth due high polymerization shrinkage $[1,2]$. Indirect restorations exhibit superior mechanical properties because its higher conversion degree extraorally reached and shrinkage stress is limited to luting cement [3]. Therefore, the clinical long-term success of an indirect restorative procedure is strongly influenced by cementation system and its sealing ability [4]

Resin cements are capable of adhere to both tooth and indirect restoration. Among these, self-adhesive cements were recently introduced and exhibit some advantages like technique sensitivity reduction (little or no room for mistakes) and less clinical steps during cementation. Application has a single clinical step, similar to conventional cements (zinc phosphate and polycarboxylate) and any pretreatment of tooth surface is required. Although several selfadhesive cements are commercially available, RelyX Unicem was the first launched and most documented in the literature [5].

Self-adhesive cements are mainly composed of conventional methacrylate monomers (Bis-GMA, UDMA, HEMA, GDMA, TEGDMA, TMPTMA) and a multifunctional phosphoric-acid methacrylate (4-META PMGDM, Phenyl-P MDP, BMP, Penta-P) that adheres to tooth surface by reacting with hydroxyapatite. After base and catalyst paste mixing, cement is placed in contact with enamel and dentin. Water from dentinal substrate ionizes the acid monomers and initial pH varies between 1.5 and 3. Smear layer is not removed and cement components do not diffuse through dentinal tubules, preventing inflammatory pulp response and post-operative sensitivity. During reaction, acid monomers bind to cement alkaline particles and dental calcium. This result in $\mathrm{pH}$ rise up to approximately 7 after 24 hours [6]. Some self-adhesive cements formulations contain calcium hydroxide that helps in $\mathrm{pH}$ neutralization. Water generated during neutralization process is consumed and cement becomes hydrophobic at the end of polymerization. This characteristic hampers the water sorption and consequent material degradation. Polymerization can be induced by light exposure (photoactivation) or just chemical (redox system), and some manufacturers advocate that self-adhesive cement shows fluoride release [6,7].
In vitro studies demonstrate that self-adhesive cement shear and microtensile bond strength to human enamel is significantly lower than etch \& rinse resin cements. When etching is performed prior self-adhesive cement application, a similar performance is observed $[7,8]$. Interactions between self-adhesive cements and dentin surface does not produce hybrid layer and resin plugs [9]. However, many studies observed bond strength values comparable to conventional resin cements $[10,11]$. Unlike enamel, dentin prior etching prejudices bonding because cement do not adequately penetrates into exposed collagen fibers.

According manufacturers, self-adhesive cements are indicated to most indirect restorations and intraradicular post-luting, regardless material (ceramic, resin or metal). Although encouraging results were registered (up to $96 \%$ success rate after 2 years), there are only shortterm clinical evaluations attesting longevity of indirect restorations luted with self-adhesive cements [12-14]. Therefore, this cement category is still not seen as first option in luting protocols.

Despite technical innovations and restorative material improvements, a concern is still present in clinical practice: marginal leakage. Also known as microleakage, it can be defined as clinical undetectable fluids passage (bacteria, molecules or ions) through a gap between cavity preparation walls and restorative material [15]. This phenomenon can result in long-term consequences as marginal discoloration, secondary caries, post-operative sensitivity pulpal pathology [16]. Gingival margins located in dentin and/or cementum

*Corresponding author: Diogo Pedrollo Lise, Departamento de Odontologia, Disciplina de Dentística, Sala 138, Universidade Federal de Santa Catarina, Campus Universitário-Trindade, CEP 88040-970, Florianópolis, Santa Catarina, Brazil, Tel: +55 48 37219880; Fax: +55 48 37219880; E-mail: diogolise@hotmail.com

Received February 11, 2014; Accepted March 03, 2014; Published March 05 2014

Citation: Lise DP, Lopes GC, Maia HP, Baratieri LN (2014) Microleakage of Composite Inlays Luted with Self-adhesive Cements. Dentistry 4: 221. doi:10.4172/2161-1122.1000221

Copyright: $\odot 2014$ Lise DP, et al. This is an open-access article distributed under the terms of the Creative Commons Attribution License, which permits unrestricted use, distribution, and reproduction in any medium, provided the original author and source are credited. 
Citation: Lise DP, Lopes GC, Maia HP, Baratieri LN (2014) Microleakage of Composite Inlays Luted with Self-adhesive Cements. Dentistry 4: 221. doi:10.4172/2161-1122.1000221

are more susceptible to microleakage due difficult access to perform a restoration, hard moisture control and substrate characteristics (less mineralized dentin and higher moisture) that hinders bonding [17].

Microleakage evaluation is required to develop techniques and materials that reduce or delay damage caused by failure of restorative marginal sealing [18]. Laboratory tests estimate material's sealing ability, and clinical significance presumes invasion of bacteria through dental substrates/restorative material interface [19]. Maximum penetration of a tracer substance seems to be best criteria on microleakage degree determination [20]. Digital photographs (large zoom and high resolution) of sectioned specimens after immersion in chemical tracer, enables proper microleakage measurement with aid of computer program [16].

Currently, scarce information about microleakage of composite resin inlays luted with self-adhesive cements is available. Thus, the aim of this in vitro research was to evaluate microleakage of three self-adhesive cements and one etches \& rinse resin cement. The null hypothesis tested was that the microleakage of the self-adhesive resin cements are similar to an etch \& rinse resin cement when bonding composite inlays to enamel and dentin margins.

\section{Materials and Methods}

Twenty-four human molars (without caries, cracks or restorations) extracted were cleaned and stored in distilled water at room temperature up to four months prior use. Teeth were vertically aligned in individual polymeric tubes and fixed with acrylic resin (Jet Dental Products Ltd. Classic., Brazil) that was poured up to $4 \mathrm{~mm}$ below cementoenamel junction. Each tooth received two strictly proximal preparations (MO and OD) for inlay restorations. A new medium-grit diamond bur (\#4130 KG Sorensen, São Paulo, Brazil) mounted on a high-speed handpiece was used for every six preparations (Figure 1). Standardized preparations comprised $3 \mathrm{~mm}$ of vestibulolingual distance and cervical margins $1 \mathrm{~mm}$ beyond cementoenamel junction (Figure 2).

Impressions of the prepared teeth were taken with an addition silicone impression material (AD Future, DFL, Rio de Janeiro, Brazil) and poured with type IV stone. Acrylic resin provisional restorations (Duralay, Reliance Dental Mfg Co Worth, USA) were placed over preparations with eugenol-free temporary cement (Temp Bond NE, Kerr, USA). Indirect restorations were incrementally manufactured using a microhybrid composite (Sinfony, 3M ESPE, USA) following manufacturer's instructions (Figure 3). Post-polymerization was

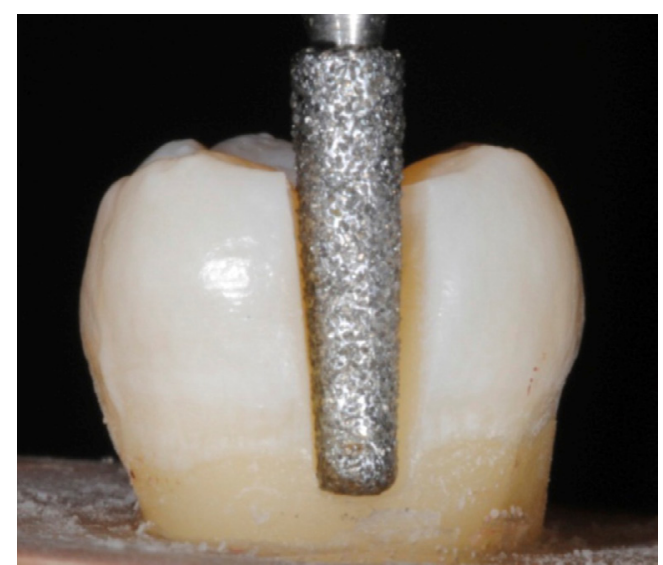

Figure 1: Diamond bur used for cavity preparation.

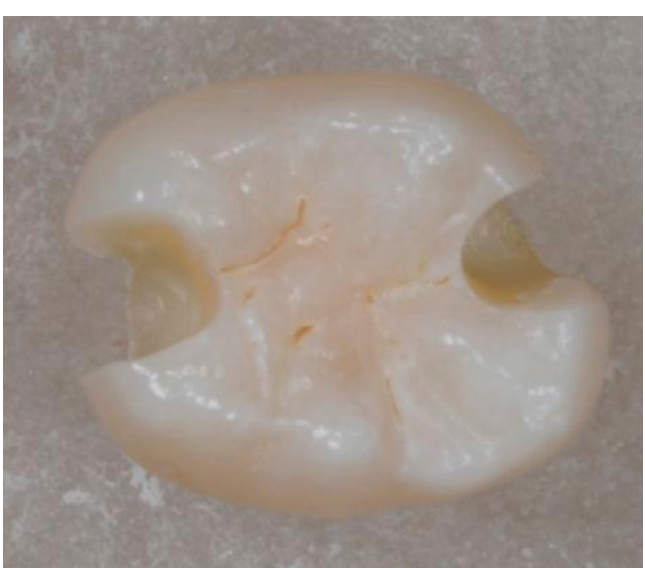

Figure 2: Two preparations per tooth.

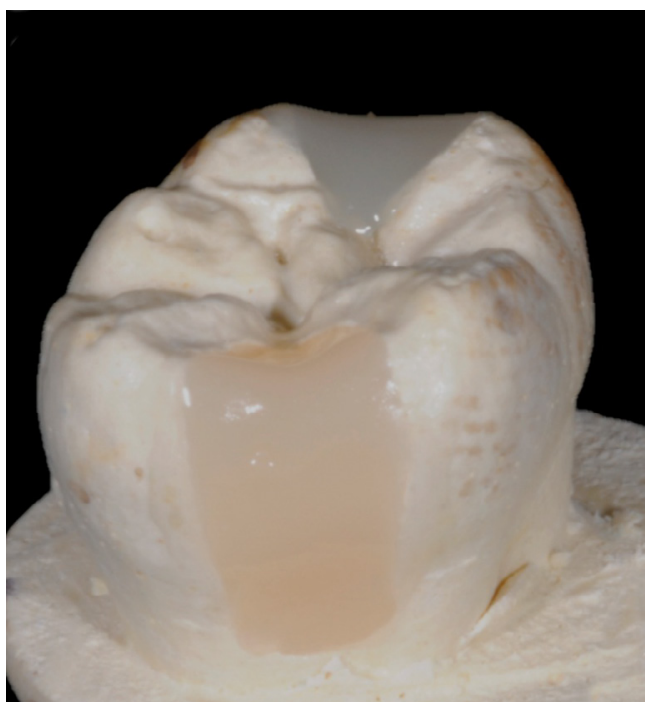

Figure 3: Indirect restorations manufactured over the cast.

conducted in specific furnace (Dentacolor XS, Heraeus-Kulzer, Germany) for 120 seconds. Internal surfaces of indirect restorations were treated by use of airborne particle abrasion (pressure of 2.5 bar) with $50 \mu \mathrm{m}$ aluminum oxide (Microetcher, Danville Engineering, USA) during 10 seconds. Then surfaces were etched with phosphoric acid 37\% (37 Condac, FGM Dental Products, Joinville, SC, Brazil) and rinsed and air dried.

Provisional restorations were removed and preparations cleaned with pumice and water. During luting four groups $(n=12)$ were randomly defined depending on cement applied (Figure 4). Luting was performed following each manufacturer's instructions (Table 1). An etch \& rinse resin cement was selected as the control group. Lightcuring was performed with a LED unit (Litex 696 LED Curing Light, Dentamerica, USA) with an output of $1.000 \mathrm{~mW} / \mathrm{cm}^{2}$.

Specimens were stored in distilled water at $37^{\circ} \mathrm{C}$ for 7 days and then were subjected to thermocycling at $5-55^{\circ} \mathrm{C}, 30$ seconds dwell time and 5 seconds transfer time (500 cycles). Root apices were sealed with a lightcured resin composite, and all surfaces were covered with two coats of quick dry nail varnish with the exception of $1 \mathrm{~mm}$ around the toothrestoration interface. The teeth were immersed into a $50 \mathrm{wt} \%$ ammoniacal 
Citation: Lise DP, Lopes GC, Maia HP, Baratieri LN (2014) Microleakage of Composite Inlays Luted with Self-adhesive Cements. Dentistry 4: 221. doi:10.4172/2161-1122.1000221

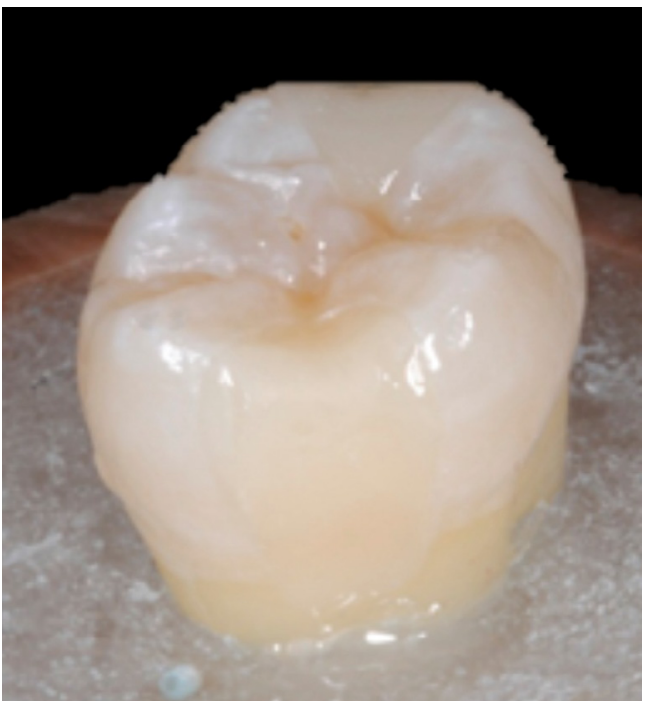

Figure 4: Restorations luted.

\begin{tabular}{|c|c|c|}
\hline & $\begin{array}{l}\text { RelyX U100 } \\
(3 M \text { ESPE) } \\
\text { Batch \#374384 }\end{array}$ & $\begin{array}{l}\text { 1. Mix cement pastes (20s). } \\
\text { 2. Apply, light-cure ( } 2 \text { s) and remove excess. } \\
\text { 3. Light-cure ( } 40 \text { s per surface). }\end{array}$ \\
\hline & $\begin{array}{l}\text { SpeedCem } \\
\text { (Ivoclar Vivadent) } \\
\text { Batch \#M32347 }\end{array}$ & $\begin{array}{l}\text { 1. Mix cement using dual syringe cartridge. } \\
\text { 2. Apply, light-cure (1s) and remove excess. } \\
\text { 3. Light-cure ( } 20 \text { s per surface). }\end{array}$ \\
\hline & $\begin{array}{l}\text { Maxcem } \\
\text { (Kerr) } \\
\text { Batch \#3498965 }\end{array}$ & $\begin{array}{l}\text { 1. Mix cement using dual syringe cartridge. } \\
\text { 2. Apply, light-cure ( } 2 \text { s) and remove excess. } \\
\text { 3. Light-cure (10s per surface). }\end{array}$ \\
\hline & $\begin{array}{l}\text { Optibond FL } \\
+ \text { Nexus } 3 \text { (Kerr) } \\
\text { Batch \#3226254 }\end{array}$ & $\begin{array}{l}\text { 1. Etch enamel/dentin with } 37 \% \text { phosphoric acid (15s) } \\
\text { rinse thoroughly and air dry. Do not desiccate. } \\
\text { 2. Apply Optibond FL Prime (15s) and air dry (5s). } \\
\text { 3. Apply Optibond FLAdhesive (15s), air thin the adhesive } \\
\text { (3s) and light-cure e fotoativar (20s). } \\
\text { 4. Mix Nexus cement using dual syringe cartridge. } \\
\text { 5. Apply, light-cure (2s) and remove excess. } \\
\text { 6. Light-cure (20s per surface). }\end{array}$ \\
\hline
\end{tabular}

Table 1: Groups, cements and indications for use.

silver nitrate solution for 24 hours (in dark), rinsed thoroughly, and then stored in a photochemical developer solution (D76, Kodak, USA) for 16 hours [21]. Three parallel longitudinal sections in the mesiodistal direction were made through the restorations using using a slow-speed and water-cooled diamond saw (Isomet, Buehler, Lake Bluff, USA). Surfaces were air dried and digitally photographed at 5.8x (1280 x 1024 resolution) under a camera coupled to a $105 \mathrm{~mm}$ lens (D3000, Nikon, Japan) and transferred to a MacBook Pro. The camera was mounted in a tripod in order to standardize the distance between the lens and the specimens. On each section, the staining along the luting interface was measured separately using image analysis software (Image J V1.34 for MacOSX, National Institutes of Health, Bethesda, Maryland, USA). Microleakage in dentin margins (along cervical wall) and enamel margins (along axial wall) was calculated in percentages considering the total length of cervical and axial wall (Figure 5). Statistical analysis was performed using Kruskall-Wallis test followed by Dunn multiple range test to notice differences among groups (significance level of $0.05)$.

\section{Results}

All test materials exhibited dye penetration along the tooth restoration interface. Statistical analysis revealed significant differences among groups $(\mathrm{P}<0.05)$. Degree of microleakage at enamel-cement interface varied between 3\% and 36\%. Microleakage of NEX group was significantly smaller than SPE. U100 and MAX groups showed intermediate sealing ability, but no statistical differences to NEX and SPE were observed (Table 2).

On dentin-cement interface, smallest microleakage degrees were attributed to U100 (52\%) and NEX (65\%). However, NEX performance was statistically similar to MAX and SPE groups (Table 2) which presented higher microleakage degrees ( $88 \%$ and $92 \%$ respectively). Considering the results, null hypotheses should be partially rejected.

\section{Discussion}

Laboratory microleakage studies are a well-accepted method of determining the marginal sealing efficiency and the performance of resin cement can be predicted. Among different methods employed, measurement of dye penetration on sections of restored teeth is the most widely accepted method [22]. In our experiment, 3 sections were made through each restoration to increase the reliability of measurements. A digital image analysis was realized to obtain quantitative results instead of conventional subjective scores. This objective approach discards the need for scoring by different evaluators and for their consensus [23].

A disadvantage of using $50 \mathrm{wt} \%$ silver nitrate solution as a tracer is that particle is extremely small $(0.059 \mathrm{~nm}$ in radius $)$ and the solution has an acidic $\mathrm{pH}(\sim 4.2)$ [24]. It has been suggested that particle penetration may be greater because of dissolution of remnant calcium phosphate salts at the adhesive interface. To avoid this, we used a buffered solution of ammoniacal silver nitrate with $\mathrm{pH}$ of $\sim 9.5$ as reported by Tay and Pashley [25].

Thermocycling was realized prior silver nitrate immersion in order to simulate thermal changes (volumetric expansion and contraction) that usually occur in the oral environment which causes stresses to resin restorations [26]. It is reported that hot water $\left(55^{\circ} \mathrm{C}\right)$ accelerates resin cement hydrolysis, enhancing water sorption and non-polymerized monomers solubility [7]. Temperature changes and differences between
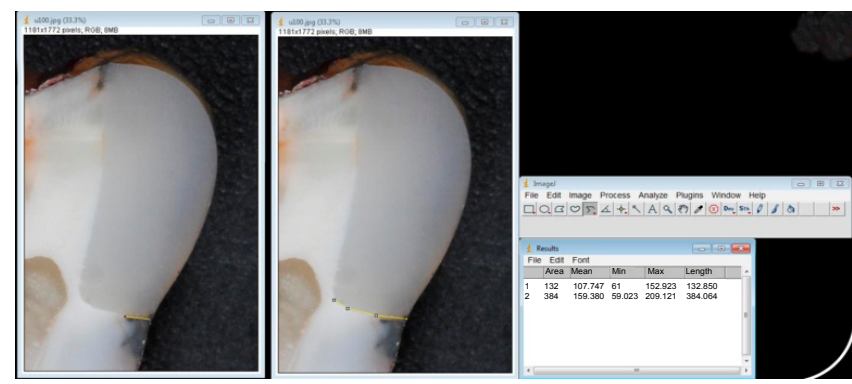

Figure 5: Microleakage measurement using computer software Image J. The yellow line in the left picture represents the maximum penetration of the tracer. The central image exhibits the measurement of the entire cervical wall. On the right image the two length measurements are used to calculate the percentage of microleakage on dentin margin. The same procedure is realized for the enamel margins.

\begin{tabular}{|c|c|c|}
\hline \multirow{2}{*}{ Resin cement } & \multicolumn{2}{|c|}{ Margin } \\
\cline { 2 - 3 } & Enamel & Dentin \\
\hline U100 & $19 \%^{\mathrm{AB}}$ & $52 \%^{\mathrm{A}}$ \\
\hline SPE & $36 \%^{\mathrm{B}}$ & $92 \%^{\mathrm{B}}$ \\
\hline MAX & $19 \%^{\mathrm{AB}}$ & $88 \%^{\mathrm{B}}$ \\
\hline NEX & $3 \%^{\mathrm{A}}$ & $65 \%^{\mathrm{AB}}$ \\
\hline
\end{tabular}

"*t*Different capital letters (in each column) indicate statistically significant difference. Table 2: Statistical analysis of tested groups. 
Citation: Lise DP, Lopes GC, Maia HP, Baratieri LN (2014) Microleakage of Composite Inlays Luted with Self-adhesive Cements. Dentistry 4: 221. doi:10.4172/2161-1122.1000221

material's thermal expansion coefficients may have induced stress on luting interface $[27,28]$. Stresses can cause gaps that may propagate through resin cement and increase microleakage [18]. In this research, artificial aging was conducted according ISO-TR 11450 protocol, which advocates only 500 thermal cycles. However, others studies suggest a greater number of cycles in order to better simulate long-term performance of self-adhesive cements [29]. Some studies also applied other artificial aging methods as thermomechanical cycling [30,31]. Furthermore, SEM evaluation seems to be an interesting strategy to supplement the interpretation of results.

Indirect resin restorations long-term quality is dependent of several factors, but type, composition and other luting agent characteristics influence microleakage degree [32]. None of adhesive cementation strategies investigated in this research has achieved a complete margin seal. The tested self-adhesive cements reached different microleakage levels which may be explained by their different functional monomers and chemical compositions. The results of this research corroborate with findings in other microleakage evaluations between self-adhesive cements and indirect restorations (metal and ceramic) [33-35].

The results showed that superior enamel margins sealing were achieved by Nexus 3 cement associated with etch \& rinse adhesive system Optibond FL. RelyX U100 and Maxcem allowed large silver nitrate penetration, however there was no statistical difference to control group. Meanwhile, the use of SpeedCem produced significantly higher microleakage degree than Nexus 3. A recent study demonstrated that self-adhesive resin cements present higher microleakage scores than etch-and-rinse resin cement at enamel margins [36].

In our study, self-adhesive cements were applied as manufacturer's instructions, without any enamel etching. De Munk et al. [37] reported lower $\mu$ TBS to enamel not previously acid-etched to the use of RelyX U100. Ibarra et al. [38] also found worse sealing ability on enamel margins when RelyX U100 was used whithout any surface conditioning. It seems that self-adhesive acid monomers have insufficient ability to etch the smear layer-covered enamel surface providing poor interprismatic hybridization and consequently weak enamel bond strength (inadequate micromechanical retention) compared with cements that preconize prior phosphoric acid etching [23]. In addition, self-adhesive cement high viscosity and short contact time with substrate prior to polymerization can explain the low etching level and higher microleakage degree [9].

A few clinical evaluations of self-adhesive cements are available. A recent controlled trial in which ceramic inlays/onlays were luted using RelyX U100 showed acceptable performance after 4 years of clinical service [39]. Moreover, additional selective enamel etching does not improve the performance of the restorations. Another in vivo study concluded that RelyX U100 showed clinical outcomes similar to a conventional multi-step cementation procedure after 2 years of clinical service [40].

The majority of previous studies demonstrate that RelyX Unicem performed comparably to other multistep resin cements on dentin $[30,41]$. This research showed the smallest microleakage degree in dentin-cement interface when RelyX U100 was used. This is atributed to multifunctional phosphoric-acid methacrylates that form complex compounds with calcium ions and physical interactions such as hydrogen bonding or dipole-to-dipole [33]. The superior performance of RelyX U100 compared with Maxcem corroborates with results of a study that evaluated shear bond strength of Synfony indirect restorations luted in dentin, where RelyX U100 reached $9 \mathrm{MPa}$, similar to etch \& rinse resin cement Variolink II (9.4 MPa) and superior than Maxcem (4.6 MPa) [42]. Another study also found similar performance of RelyX U100 and Varolink II when used for ceramic veneer cementation [38].

Future studies are needed to address whether new strategies can be used in order to improve the bond strength of self-adhesive cements.

\section{Conclusions}

Within the limitations of this in vitro study, it can be concluded that among self-adhesive resin cements, RelyX U100 showed the best sealing ability of dentin margins and its performance was comparable to control etch \& rinse resin cement. Despite enamel margins, RelyX U100 and Maxcem displayed similar microleakage scores to control group.

\section{References}

1. Ferracane JL (2008) Buonocore Lecture. Placing dental composites--a stressfu experience. Oper Dent 33: 247-257.

2. Dietschi D, Monasevic M, Krejci I, Davidson C (2002) Marginal and interna adaptation of class II restorations after immediate or delayed composite placement. J Dent 30: 259-269.

3. Knobloch LA, Kerby RE, Seghi R, van Putten M (1999) Two-body wear resistance and degree of conversion of laboratory-processed composite materials. Int J Prosthodont 12: 432-438.

4. Jayasooriya PR, Pereira PNR, Nikaido T, Tagami J (2003) Efficacy of a resin coating on bond strengths of resin cement to dentin. J Esthet Restor Dent 15 $105-113$

5. Radovic I, Monticelli F, Goracci C, Vulicevic ZR, Ferrari M (2008) Self-adhesive resin cements: a literature review. J Adhes Dent 10: 251-258.

6. Han L, Okamoto A, Fukushima M, Okiji T (2007) Evaluation of physical properties and surface degradation of self-adhesive resin cements. Dent Mater J 26: 906-914.

7. De Munck J, Vargas M, Van Landuyt K, Hikita K, Lambrechts P, et al. (2004) Bonding of an auto-adhesive luting material to enamel and dentin. Dent Mater 20: 963-971.

8. Benetti P, Fernandes VV, Torres CR, Pagani C (2011) Bonding efficacy of new self-etching, self-adhesive dual-curing resin cements to dental enamel. J Adhes Dent 13: 231-234.

9. Monticelli F, Osorio R, Mazzitelli C, Ferrari M, Toledano M (2008) Limited decalcification/diffusion of self-adhesive cements into dentin. J Dent Res 87: 974-979.

10. Vaz RR, Di Hipólito V, Perlatti D'Alpino PH, de Goes MF (2011) Bond Strength and Interfacial Micromorphology of Etch-and-Rinse and Self-Adhesive Resin Cements to Dentin. J Prosthodont 1: 1-11.

11. Türkmen C, Durkan M, Cimilli H, Öksüz M (2011) Tensile bond strength of indirect composites luted with three new self-adhesive resin cements to dentin. J Appl Oral Sci 19: 363-369.

12. Schenke F, Federlin M, Hiller KA, Moder D, Schmalz G (2012) Controlled prospective, randomized, clinical evaluation of partial ceramic crowns inserted with RelyX Unicem with or without selective enamel etching. Clin Oral Invest 16: 451-461.

13. Peumans M, De Munck J, Van Landuyt K, Poitevin A, Lambrechts $P$, et al (2010) Two-year clinical evaluation of a self-adhesive luting agent for ceramic inlays. J Adhes Dent 12: 151-161.

14. Taschner M, Frankenberger R, García-Godoy F, Rosenbusch S, Petschelt A, et al. (2009) IPS Empress inlays luted with a self-adhesive resin cement after 1 year. Am J Dent 22: 55-59.

15. Kidd EA (1976) Microleakage: a review. J Dent 4: 199-206.

16. Pazinatto FB, Atta MT (2004) Microleakage studies: Critical analysis of methodology. JBD 10: 207-215.

17. Araujo F de O, Vieira LCC, Monteiro Junior S (2006) Influence of resin composite shade and location of the gingival margin on the microleakage of posterior restorations. Oper Dent 31: 556-561. 
Citation: Lise DP, Lopes GC, Maia HP, Baratieri LN (2014) Microleakage of Composite Inlays Luted with Self-adhesive Cements. Dentistry 4: 221. doi:10.4172/2161-1122.1000221

18. Taylor MJ, Lynch E (1992) Microleakage. J Dent 20: 3-10.

19. Söderholm KJ (1991) Correlation of in vivo and in vitro performance of adhesive restorative materials: a report of the ASC MD156 Task Group on Test Methods for the Adhesion of Restorative Materials. Dent Mater 7: 74-83.

20. Raskin A, D'Hoore W, Gonthier S, Degrange M, Déjou J (2001) Reliability of in vitro microleakage tests: a literature review. J Adhes Dent 3: 295-308.

21. Tay FR, Pashley DH, Yoshiyama M (2002) Two modes of nanoleakage expression in single-step adhesives. J Dent Res 81: 472-476.

22. Raskin A, Tassery H, D'hoore W, Gonthier S, Vreven J, et al. (2003) Influence of the number of specimens on reliability of in vitro microleakage evaluations. Am J Dent 6: 207-210.

23. Cehreli ZC, Gungor HC (2008) Quantitative microleakage evaluation of fissure sealants applied with or without a bonding agent: results after four-year water storage in vitro. J Adhes Dent 10: 379-384

24. Alani AH, Toh CG (1997) Detection of microleakage around dental restorations: a review. Oper Dent 22: 173-185.

25. Tay FR, Pashley DH (2003) Water treeing - a potential mechanism for degradation of dentin adhesives. Am J Dent 16: 6-12.

26. International Organization for Standardization (1994) TR 11405 - Dental materials-guidance on testing of adhesion to tooth structure.

27. Gale MS, Darvell BW (1999) Thermal cycling procedures for laboratory testing of dental restorations. J Dent 27: 89-99.

28. De Munck J, Van Landuyt K, Peumans M, Poitevin A, Lambrechts P, et al. (2005) A critical review of the durability of adhesion to tooth tissue: methods and results. J Dent Res 84: 118-132.

29. Attia A (2012) Influence of treatment modalities of prepared teeth on retention of cast metal copings bonded with self-adhesive resin cements. Quintessence Int 43: 73-81.

30. Rosentritt M, Behr M, Lang R, Handel G (2004) Influence of cement type on the marginal adaptation of all-ceramic MOD inlays. Dent Mater 20: 463-469.
31. Behr M, Rosentritt M, Regnet T, Lang R, Handel G (2004) Marginal adaptation in dentin of a self-adhesive universal resin cement compared with well-tried systems. Dent Mater 20: 191-197.

32. Wu W, Cobb EN (1981) A silver staining technique for investigating wear of restorative dental composites. J Biomed Mater Res 15: 343-348.

33. Piwowarczyk A, Lauer H-C, Sorensen JA (2005) Microleakage of various cementing agents for full cast crowns. Dent Mater 21: 445-453.

34. Fabianelli A, Goracci C, Bertelli E, Monticelli F, Grandini S, et al. (2005) In vitro evaluation of wall-to-wall adaptation of a self-adhesive resin cement used for luting gold and ceramic inlays. J Adhes Dent 7: 33-40.

35. Hooshmand T, Mohajerfar M, Keshvad A, Motahhary P (2011) Microleakage and marginal gap of adhesive cements for noble alloy full cast crowns. Oper Dent 36: 258-265.

36. Cal E, Celik EU, Turkun M (2012) Microleakage of IPS empress 2 inlay restorations luted with self-adhesive resin cements. Oper Dent 37: 417-424.

37. De Munk J, Vargas MA, Van Landuyt K, Hikita K, Lambrechts P, et al. (2004) Bonding of an auto-adhesive luting material to enamel and dentin. Dent Mater 20: $963-971$.

38. Ibarra G, Johnson GH, Geurtsen W, Vargas MA (2007) Microleakage of porcelain veneer restorations bonded to enamel and dentin with a new selfadhesive resin-based dental cement. Dent Mater 23: 218-225.

39. Peumans M, Voet M, De Munck K, Van Landuyt K, Van Ende A, et al. (2013) Four-year clinical evaluation of a self-adhesive luting agent for ceramic inlays. Clin Oral Investig 17: 739-750.

40. Taschner M, Krämer N, Lohbauer U, Pelka M, Breschi L, et al. (2012) Leucitereinforced glass ceramic inlays luted with self-adhesive resin cement: a 2-year in vivo study. Dent Mater 28: 535-540.

41. Fabianelli A, Goracci C, Bertelli E, Monticelli F, Grandini S, et al. (2005) In vitro evaluation of wall-to-wall adaptation of a self-adhesive resin cement used for luting gold and ceramic inlays. J Adhes Dent 7: 33-40.

42. Peutzfeldt A, Sahafi A, Flury S (2011) Bonding of restorative materials to dentin with various luting agents. Oper Dent 36: 266-273. 